\title{
René Char 2. Poètes et philosophes. De la fraternité selon Char, textes réunis par Danièle Leclair et Patrick Née, «La Revue des Lettres Modernes»
}

\section{Sara Arena}

\section{(2) OpenEdition}

\section{Journals}

\section{Edizione digitale}

URL: http://journals.openedition.org/studifrancesi/8076

DOI: $10.4000 /$ studifrancesi.8076

ISSN: 2421-5856

\section{Editore}

Rosenberg \& Sellier

\section{Edizione cartacea}

Data di pubblicazione: 1 juillet 2009

Paginazione: 440-441

ISSN: 0039-2944

\section{Notizia bibliografica digitale}

Sara Arena, «René Char 2. Poètes et philosophes. De la fraternité selon Char, textes réunis par Danièle Leclair et Patrick Née, "La Revue des Lettres Modernes»», Studi Francesi [Online], 158 (LIII | II) | 2009, online dal 30 novembre 2015, consultato il 13 janvier 2021. URL: http://journals.openedition.org/ studifrancesi/8076 ; DOI: https://doi.org/10.4000/studifrancesi.8076

Questo documento è stato generato automaticamente il 13 janvier 2021.

\section{cc) (†)}

Studi Francesi è distribuita con Licenza Creative Commons Attribuzione - Non commerciale - Non opere derivate 4.0 Internazionale. 


\title{
René Char 2. Poètes et philosophes. De la fraternité selon Char, textes réunis par Danièle Leclair et Patrick Née, «La Revue des Lettres Modernes»
}

\author{
Sara Arena
}

\section{NOTIZIA}

René Char 2. Poètes et philosophes. De la fraternité selon Char, textes réunis par Danièle LECLAIR et Patrick NÉE, «La Revue des Lettres Modernes», 2007, pp. 268.

Dopo il primo numero apparso nel 2005, il secondo volume dedicato dalla «Revue des Lettres Modernes» alla figura di René Char esplora i rapporti del poeta con i suoi «frères en poésie» (p. 5): poeti, artisti e filosofi coevi con cui intrattenne rapporti di amicizia e stima letteraria, ma anche grandi precursori e fonti di ispirazione del passato recente e remoto, fino agli autori della classicità.

2 La prima parte del testo, che raccoglie gli interventi relativi a Les "grands ascendants", è aperta dallo studio di Danièle LECLAIR (La Grèce en source: fraternité de Char avec Homère, pp. 9-52) sul ruolo giocato, tra le letture di René Char, dai poemi omerici, a cui l'opera del poeta è accomunata in particolare da un'acuta percezione della drammaticità della storia umana. Corinne BAYLE (René Char et le Romantisme de la Nuit, pp. 53-80) ripercorre il legame dei testi di Char con la poetica del Romanticismo, tedesco e in parte francese, con una speciale attenzione alle tematiche legate al regime notturno. Tra le assonanze con grandi autori precedenti, è poi rilevata la vicinanza con la filosofia nietzscheana dell'eterno ritorno, studiata da Patrick NÉE (Char et Nietzsche ou de l'Éternel retour, pp. 81-116) e quella con l'opera di Rimbaud, che Martine CRÉAC'H studia concentrandosi su una singola citazione inserita da Char nella raccolta Aromates classeurs ( VVoici le temps des assassins!): lire Rimbaud avec Char dans "Aromates chasseurs", pp. 117-139). 
3 La seconda parte del volume, Chemins croisés, raccoglie invece interventi relativi ad autori temporalmente vicini a Char, che ebbero talora con il poeta un rapporto diretto, di ammirazione, amicizia o suggestione, come nel caso di Jacques Dupin, particolarmente sensibile all'opera "notturna" di Char (Anne GouRIO, Aux sources de la nuit - Char et Dupin: genèse d'un imaginaire, pp. 145-172), e Pierre-Albert Jourdan, la cui opera mostra con quella di Char alcune importanti tangenze, sia pur accompagnate da differenze strutturali nel trattamento della componente figurativa, del tempo e dell'enunciazione (Stéphanie THONNÉRIEUx, René Char et Pierre-Albert Jourdan: mesures d'un voisinage, pp. 173-194).

4 Patrick QUILLIER studia il legame, spesso evocato dalla critica ma contraddetto dallo stesso Char, tra i testi del poeta e la filosofia di Heidegger, approfondendo in particolare la concezione dei due autori circa la questione del «silence absolu» (p. 195) e della nominazione (Du silence au verbe: l'écoute métaphysique selon Char et selon Heidegger, pp. 195-220). Céline GUILLOT studia la natura del rapporto che Char intrattenne con Maurice Blanchot attraverso le poesie scritte dallo stesso Char "in risposta" ai numerosi articoli critici di Blanchot e mette in evidenza analogie e differenze nella visione di un tema caro a entrambi come quello del conturbante incontro con l'altro, con l'“amico", figura che riassume in sé il simile e l'ignoto («Dans le ciel des hommes....): une conversation entre René Char et Maurice Blanchot, pp. 221-244).

In René Char, la fraternité et la culture populaire (pp. 245-267), Bengt NovéN aggiunge infine un ulteriore tassello alla dimensione della "fraternità" nella vita e nell'opera di René Char presentando un'analisi della dimensione popolare dei suoi testi, che convive con la componente astratta, ermetica e per certi versi elitaria della sua scrittura e trova talora voce in elementi del paratesto come la dedica, le prefazioni e i numerosi omaggi, nonché in alcuni testi ispirati all'esperienza della Resistenza e in alcune dichiarazioni rilasciate dal poeta stesso sulla sua visione della letteratura come "attività manuale" ( Je ne suis pas un professionnel de la littérature. J'ai la chance d'avoir une terre que je cultive...», p. 250). 